\title{
Dental Hygienist
}

National Cancer Institute

\section{Source}

National Cancer Institute. Dental Hygienist. NCI Thesaurus. Code C53293.

A health care professional auxiliary in dentistry trained and licensed to provide preventive, therapeutic and educational services for the control of oral diseases. 